\title{
Effects of terbutaline in combination with mannitol on mucociliary clearance
}

\author{
E. Daviskas*, S.D. Anderson*, S. Eberl", H-K. Chan", I.H. Young*, J.P. Seale ${ }^{+}$
}

Effects of terbutaline in combination with mannitol on mucociliary clearance. E. Daviskas, S.D. Anderson, S. Eberl, H-K. Chan, I.H. Young, J.P. Seale. (C)ERS Journals Ltd 2002.

ABSTRACT: $\beta_{2}$-agonists and osmotic agents stimulate mucociliary clearance (MCC) via different mechanisms which could potentially interact.

The effects of inhaling terbutaline in combination with mannitol on MCC were investigated in nine healthy (aged $19 \pm 1$ yrs) and 11 mild (aged $21 \pm 4$ yrs) asthmatic subjects. Using ${ }^{99 m}$ Tc-sulphur colloid radioaerosol and a gamma camera, MCC was studied on four separate days with each of the following interventions: 1) terbutaline or its placebo inhaled 10 min before mannitol (in random, double blind); 2) terbutaline inhaled $5 \mathrm{~min}$ after mannitol; and 3) terbutaline inhaled $10 \mathrm{~min}$ before the control for mannitol. Lung images were collected over a period of $120 \mathrm{~min}$ postintervention and over $150 \mathrm{~min}$ in total.

The mannitol-induced increase in clearance was transiently inhibited by terbutaline pretreatment and transiently enhanced when terbutaline was administered after mannitol both in asthmatic and healthy subjects. The order of administration of mannitol and terbutaline did not affect the total clearance of radioactive mucus over 140 min from the start of intervention in both groups.

The pathways through which terbutaline and mannitol increase mucociliary clearance may transiently interact in an inhibitory or synergistic way, depending on the order of administration. However, this did not affect the overall increase in mucociliary clearance over $140 \mathrm{~min}$.

Eur Respir J 2002; 20: 1423-1429.
*Depts of Respiratory and ${ }^{\#}$ Positron Emission Tomography and Nuclear Medicine, Royal Prince Alfred Hospital, Camperdown, and "Depts of Pharmacy and ${ }^{+}$Pharmacology, University of Sydney, Sydney, Australia.

Correspondence: E. Daviskas, Respiratory Medicine, E11 South, Royal Prince Alfred Hospital, Missenden Road, Camperdown, NSW 2050, Australia. Fax: 61295158196

E-mail: lily@nucmed.rpa.cs.nsw.gov.au

Keywords: Hyperosmolarity, mannitol, mucociliary clearance, terbutaline

Received: December 102001

Accepted after revision: June 112002

The study was supported by a grant from the National Health and Medical Research Council of Australia. The application for the use of mannitol described in the paper is covered by US Patent No 5817028, an Australian Patent No 682756 and an International Patent PCT/AU 95/00086 held by Central Sydney Area Health Service.
Normal mucociliary clearance (MCC) has a reserve capacity that can be stimulated by various intrinsic or extrinsic agents. The $\beta_{2}$-agonist, terbutaline, stimulates ciliary beat frequency $(\mathrm{CBF})[1,2]$ and increases MCC in healthy and mild asthmatic subjects [3, 4]. The effects of the $\beta_{2}$-agonists on the airways are mediated by the $\beta_{2}$-receptors, stimulation of which increases cyclic adenosine monophosphate (cAMP). cAMP is a regulator of $\mathrm{CBF}$ in human airway epithelia $[5,6]$.

Osmotic agents such as hypertonic saline and mannitol also increase MCC in healthy and mild asthmatic subjects [7, 8]. These osmotic stimuli improve MCC in patients with impaired baseline clearance and excessive and viscous mucus such as patients with cystic fibrosis $[9,10]$ and with bronchiectasis $[11,12]$. The mechanism whereby osmotic agents stimulate MCC probably involves a combination of factors which lead to an increase in ciliary activity and an improvement in the physical properties of mucus, thus favouring ciliary and cough clearance [13]. Osmotic agents have been reported to stimulate CBF in vivo [14] and to increase ciliary transportability of sputum [15]. Stimulation of CBF is likely to involve calcium as the cellular events in response to hyperosmolarity of the airway fluid lead to an increase in intracellular calcium $\left(\left[\mathrm{Ca}^{2+}\right]_{\mathrm{i}}\right)[16,17]$. In addition, mediators released in response to hyperosmolarity [18], such as histamine and neuropeptides that stimulate CBF [19, 20] and increase MCC [21], have also been reported to cause an increase in $\left[\mathrm{Ca}^{2+}\right]_{\mathrm{i}}$ $[22,23]$.

Therefore, $\beta_{2}$-agonists and osmotic agents probably stimulate MCC via different pathways which could potentially interact. This study investigated the effect of terbutaline in combination with dry powder mannitol on the acute stimulation of MCC in healthy and mild asthmatic subjects. Healthy and mild asthmatic subjects were used as both are known to have normal baseline MCC and have demonstrated an increase of the reserve capacity of the mucociliary system with mannitol [8] and terbutaline [3, 4].

\section{Subjects}

\section{Methods}

Eleven mild asthmatic and nine healthy nonsmoking subjects participated and completed the 
study (table 1). Asthmatic subjects were included in the study if they met the following criteria: 1) prior to the studies they were clinically stable, their forced expiratory volume in one second (FEV1) was $>80 \%$ predicted; 2) they could withhold the short acting $\beta_{2}$-agonist and corticosteroid medication for $8 \mathrm{~h}$ and the long acting $\beta_{2}$-agonist for $48 \mathrm{~h} ; 3$ ) theophylline was not part of their medication; 4) they could withhold antihistaminic and nonsteroidal antiinflammatory medication for at least $72 \mathrm{~h}$; and 5) they did not have a lower respiratory tract infection for 6 weeks prior to the study.

The study was approved by the Ethics Committee of the Central Sydney Area Health Service (Protocol No: X99- 0058).

\section{Measurement of lung function}

Spirometry was measured using a hot-wire anemometer (AS-500; Minato, Osaka, Japan), before and after inhalation of mannitol, on the first visit and before the radioaerosol inhalation on the MCC study days. Predicted values were taken from the paper by QUANJER et al. [24] for adults.

\section{Terbutaline}

Terbutaline sulphate (1 mg) (Astra pharmaceuticals, Lund, Sweden) from a metered-dose inhaler was used, as this has been shown to stimulate MCC in asthmatic and healthy subjects [3, 4] and it is commonly used in asthma and other lung diseases. The terbutaline placebo was its vehicle (Astra pharmaceuticals, Lund, Sweden). Both terbutaline and its placebo were delivered via a spacer (Nebuhaler ${ }^{\mathrm{TM}}$ ). As all subjects had normal baseline lung function on the assessment day, the bronchodilating effect of terbutaline was assessed after the mannitol challenge.

\section{Mannitol}

The preparation of the dry powder mannitol (Mannitol BP; Rhône Poulenc Chemicals, Pty, Ltd, Brookvale, NSW, Australia) has been described in detail previously $[8,11,12]$. The mannitol powder was inhaled from capsules with a vital capacity manoeuvre and an inspiratory flow of $60 \mathrm{~L} \cdot \mathrm{min}^{-1}$ followed by a breath hold of $5 \mathrm{~s}$ using a dry powder inhaler (Inhalator ${ }^{\mathrm{TM}}$; Boehringer Ingelheim, Ingelheim, Germany). Sixty-five per cent of mannitol particles by mass in the aerosol clouds generated from the Inhalator ${ }^{\mathrm{TM}}$ at $60 \mathrm{~L} \cdot \mathrm{min}^{-1}$ were $<7 \mu \mathrm{m}$, as characterised using a multiple-stage liquid impinger.

An airway response to mannitol was performed in both the asthmatic and healthy subjects following an established protocol [25] comprising cumulative doses of 0 (empty capsule acting as a placebo), 5, 10, 20, 40, $80,160,160,160 \mathrm{mg}$ mannitol. The FEV1 value

Table 1. - Anthropometric data, baseline forced expiratory volume in one second (FEV 1 ), airway responses to mannitol in asthmatic and healthy subjects and medication taken by the asthmatic subjects

\begin{tabular}{|c|c|c|c|c|c|c|c|c|c|c|c|}
\hline \multirow[t]{2}{*}{ Subjects } & \multirow{2}{*}{$\begin{array}{l}\text { Age } \\
\text { yrs }\end{array}$} & \multirow[t]{2}{*}{ Sex } & \multirow{2}{*}{$\begin{array}{l}\text { Height } \\
\mathrm{cm}\end{array}$} & \multirow{2}{*}{$\begin{array}{c}\text { Baseline } \\
\mathrm{FEV}_{1} \% \\
\text { pred }\end{array}$} & \multirow{2}{*}{$\begin{array}{l}\text { FEV1/ } \\
\text { FVC } \%\end{array}$} & \multirow{2}{*}{$\begin{array}{l}\text { Postdilator } \\
\text { FEV1 } \% \text { pred }\end{array}$} & \multirow{2}{*}{$\begin{array}{l}\text { Mannitol } \\
\text { loaded } \\
\text { dose mg }\end{array}$} & \multirow{2}{*}{$\underset{\%}{\text { Fall FEV1 }}$} & \multicolumn{3}{|c|}{ Medication } \\
\hline & & & & & & & & & Drug & $\begin{array}{l}\text { Steroid daily } \\
\text { dose } \mu \mathrm{g}\end{array}$ & $\begin{array}{l}\text { Time on } \\
\text { months }\end{array}$ \\
\hline \multicolumn{12}{|c|}{ Asthmatic } \\
\hline 1 & 20 & $\mathrm{~F}$ & 185 & 108 & 79 & 108 & 315 & 19 & $\mathrm{~S}, \mathrm{BEC}$ & 500 & 12 \\
\hline 2 & 18 & F & 174 & 80 & 70 & 87 & 195 & 17 & $\mathrm{~T}$ & & \\
\hline 3 & 19 & $\mathrm{~F}$ & 171 & 103 & 103 & 105 & 135 & 19 & $\mathrm{~S}$ & & \\
\hline 4 & 18 & $\mathrm{~F}$ & 182 & 98 & 89 & 101 & 480 & 21 & $\mathrm{~S}$ & & \\
\hline 5 & 19 & $\mathrm{~F}$ & 156 & 107 & 86 & 107 & 75 & 20 & $\mathrm{~T}$ & & \\
\hline 6 & 25 & $\mathrm{~F}$ & 158 & 80 & 90 & 80 & 195 & 18 & SER, FL & 500 & 4 \\
\hline 7 & 20 & M & 165 & 95 & 83 & 95 & 155 & 34 & S, BEC & 500 & 60 \\
\hline 8 & 22 & M & 161 & 108 & 95 & 110 & 355 & 18 & S, BUD & 400 & 24 \\
\hline 9 & 30 & M & 173 & 83 & 74 & 85 & 315 & 19 & $\mathrm{~S}$ & & \\
\hline 10 & 21 & $\mathrm{~F}$ & 165 & 94 & 74 & 96 & 555 & 16 & FL & 250 & 24 \\
\hline 11 & 18 & M & 177 & 93 & 82 & 95 & 395 & 21 & S, BUD & 600 & $>60$ \\
\hline Mean & 21 & & 170 & 95 & 84 & 97 & 288 & 20 & & & \\
\hline SD & 4 & & 10 & 11 & 10 & 10 & 151 & 5 & & & \\
\hline \multicolumn{12}{|l|}{ Healthy } \\
\hline 1 & 18 & $\mathrm{~F}$ & 159 & 119 & 95 & 121 & 400 & 1 & & & \\
\hline 2 & 18 & $\mathrm{~F}$ & 164 & 104 & 86 & 104 & 400 & 8 & & & \\
\hline 3 & 18 & $\mathrm{~F}$ & 165 & 89 & 84 & 96 & 400 & 0 & & & \\
\hline 4 & 18 & $\mathrm{~F}$ & 174 & 100 & 97 & 101 & 400 & 2 & & & \\
\hline 5 & 18 & $\mathrm{M}$ & 177 & 110 & 81 & 114 & 400 & 3 & & & \\
\hline 6 & 19 & M & 188 & 102 & 79 & 105 & 400 & 4 & & & \\
\hline 7 & 21 & $\mathrm{M}$ & 182 & 96 & 78 & 98 & 400 & 3 & & & \\
\hline 8 & 19 & M & 166 & 101 & 89 & 105 & 400 & 3 & & & \\
\hline 9 & 19 & M & 166 & 101 & 98 & 101 & 400 & 8 & & & \\
\hline Mean & 19 & & 171 & 102 & 87 & & 400 & 3 & & & \\
\hline SD & 1 & & 10 & 8 & 8 & & 0 & 3 & & & \\
\hline
\end{tabular}

FVC: forced vital capacity; F: female; M: male; S: salbutamol; BEC: beclamethasone; T: terbutaline; SER: serevent; FL: flixotide; BUD: budesonide. 
measured after the $0 \mathrm{mg}$ capsule was taken as the baseline against which the per cent fall in FEV1 in response to mannitol challenge was calculated. Spirometry was measured initially and within 1 min after each dose of mannitol. The challenge was stopped if the fall in FEV 1 was $>15 \%$ in asthmatic subjects. The cumulative dose of mannitol inhaled on the challenge day determined the dose that asthmatics inhaled on the MCC visit. The healthy subjects were assessed similarly but the cumulative dose of mannitol was $400 \mathrm{mg}$, as this dose was used to increase clearance in the past studies [8]. On the MCC visits the dose of mannitol, as determined on visit 1 (table 1), was inhaled progressively, without the intervening spirometric measurements.

\section{Measurement of mucociliary clearance}

The technique for measuring MCC involved inhaling a radioaerosol and imaging using a gamma camera. Details of the technique have been published previously $[7,11,12]$.

Inhalation of radioaerosol. In brief, the radioaerosol, ${ }^{99 m}$ Tc-sulphur colloid (Chedoke-McMaster Hospitals, Hamilton, ON, Canada) (mass median aerodynamic diameter $6 \mu \mathrm{m}$, span 1.8), was generated by an Acorn jet nebuliser (Medic-Aid, Peckham, Sussex, UK) at $8 \mathrm{~L} \cdot \mathrm{min}^{-1}$. Patients inhaled the radioaerosol (for $\sim 2 \mathrm{~min}$ ) with a controlled breathing pattern, following a target volume $(450 \mathrm{~mL})$ and a target inspiratory flow $\left(\sim 50 \mathrm{~L} \cdot \mathrm{min}^{-1}\right)$ on a computer screen, for maximum deposition in the conducting airways.

Imaging. Anterior and posterior lung images were obtained, with the patient in the supine position, using a single head rotating gamma camera (Philips Diagnost Tomo, Hamburg, Germany). The lung fields were delineated with anterior and posterior transmission images taken with a moving line source.

\section{Data image analysis}

All images were decay corrected to the time of midinhalation of the radioaerosol. Geometric mean images (GM) were obtained from the anterior and posterior transmission and emission images. The right lung was divided into three regions of interest: central, intermediate and peripheral. The left lung was not analysed due to possible interference from the activity in the stomach. The initial lung radioaerosol distribution was characterised by the ratio of the counts per pixel in the peripheral to the counts per pixel in the central region (penetration index) in the GM emission image obtained $10 \mathrm{~min}$ after the mid-inhalation of the radioaerosol.

A mono- or bi-exponential function was fitted to each curve obtained from the dynamic GM images, using a nonlinear least squares method (IDL 5.0; Research Systems Inc, Boulder, CO, USA). The total counts of the whole right lung and defined regions in the first emission GM image were taken as the initial counts expressed as $100 \%$ retention. The counts of the whole right lung and defined regions in the dynamic emission GM images, measured before and after the intervention, were expressed as percentage of the initial counts. Data from the best fit were used to calculate the per cent clearance at specified intervals and the per cent clearance per min initially, during intervention and for each $10 \mathrm{~min}$ interval postintervention.

\section{Study design}

The study involved five visits at least $48 \mathrm{~h}$ apart. On visit 1 , the baseline lung function, the airway challenge with mannitol and the bronchodilator response to terbutaline was assessed. On visits 2-5, MCC was assessed in response to terbutaline and mannitol. The procedure on visits 2-5 was as follows: 1) spirometry; 2) radioaerosol inhalation; 3) static emission images (1 min each) $10 \mathrm{~min}$ after the radioaerosol inhalation to assess its initial deposition; 4) dynamic emission images (20 s each) for $10 \mathrm{~min}$ to assess initial MCC; 5) intervention; and 6) dynamic emission images (20 s each) for $120 \mathrm{~min}$ to assess the effect of the intervention on MCC.

The intervention was: 1) inhalation of terbutaline $(1 \mathrm{mg})$ followed $10 \mathrm{~min}$ later by inhalation of mannitol; or 2) inhalation of terbutaline placebo followed 10 min later by mannitol; or 3) inhalation of mannitol followed $5 \mathrm{~min}$ later by inhalation of terbutaline $(1 \mathrm{mg})$; or 4$)$ inhalation of terbutaline $(1 \mathrm{mg})$ followed 10 minutes later by control for mannitol. The first two studies involved terbutaline or its placebo given in random order double-blind. The control for mannitol involved inhaling through the dry powder inhaler device loaded with an empty capsule and performing the maximum number of coughs that occurred during mannitol inhalation. The study involving terbutaline and mannitol control was last. The total time of intervention ( $20 \mathrm{~min})$ was matched as closely as possible on all visits.

As both terbutaline and mannitol have been seen to increase MCC previously [3, 8], no placebo control or baseline studies were included in this study.

\section{Statistical analysis}

A two-factor analysis of variance (ANOVA), with repeated measures, was performed on the calculated clearance rate at the same specified intervals on the four study days. Post-hoc analysis was performed using Duncan's new multiple range test.

Spearman's correlation analysis was performed between the changes in the clearance and the changes in cough between the studies involving terbutaline or placebo before mannitol. Probability values $<0.05$ were considered statistically significant. Results are reported as mean \pm SEM. 


\section{Results}

\section{Initial clearance}

There was no significant difference in the preintervention clearance measured during the first 10 min on all study days in the whole right lung and defined regions in both groups ( $p>0.3)$ (fig. 1).

\section{Effect of intervention}

During the intervention interval, the immediate increase in clearance rate in response to mannitol was inhibited by terbutaline pretreatment $(0.75 \pm$ $0.12 \% \cdot \mathrm{min}^{-1}$ in asthmatic, $0.75 \pm 0.11 \% \cdot \mathrm{min}^{-1}$ in healthy) compared to its placebo pretreatment (1.32 \pm $0.33 \% \cdot \mathrm{min}^{-1}$ in asthmatic, $1.05 \pm 0.14 \% \cdot \mathrm{min}^{-1}$ in healthy) in the whole right lung, $(p=0.0001)$ (fig. 2). By

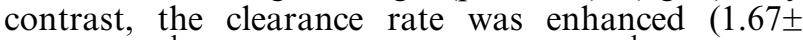
$0.21 \% \cdot \mathrm{min}^{-1}$ in asthmatic, $1.59 \pm 0.21 \% \cdot \mathrm{min}^{-1}$ in healthy)
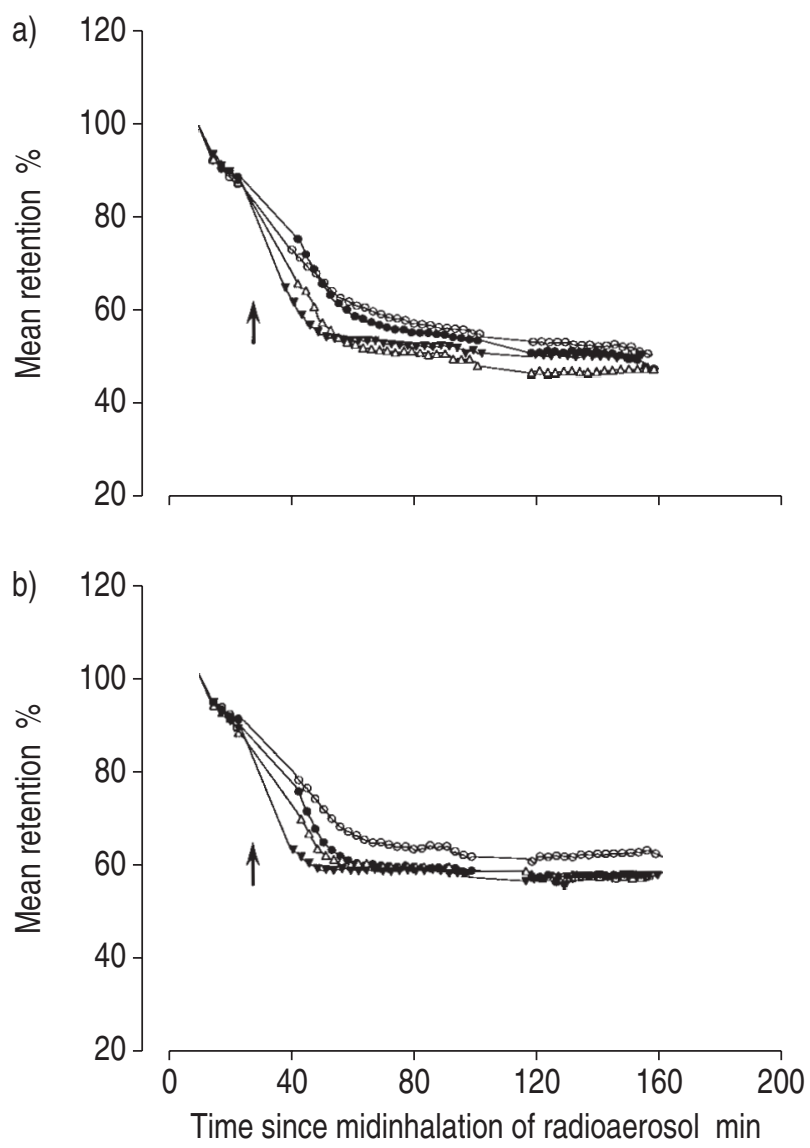

Fig. 1.-Mean per cent retention curves of the four studies involving: 1) terbutaline before mannitol $(\mathbf{O})$; 2) placebo before mannitol $(\triangle)$; 3) terbutaline after mannitol $(\boldsymbol{\nabla})$; and 4) terbutaline before mannitol control (cough control) $(\bigcirc)$ in the whole right lung, in a) 11 asthmatic and b) nine healthy subjects. The arrow indicates intervention. The retained activity over time is normalised based on the initial radioactivity measured $10 \mathrm{~min}$ after the inhalation of the radioaerosol. Clearance at a specified time is calculated as 100 minus the retained activity. This figure demonstrates the differences in the clearance during intervention and immediately afterwards. when terbutaline was inhaled after mannitol, compared to its placebo before mannitol, in the whole right lung, ( $\mathrm{p}=0.0001)$ (fig. 2). The clearance rate was similar when terbutaline was inhaled first either before mannitol $\left(0.75 \pm 0.12 \% \cdot \mathrm{min}^{-1}, 0.75 \pm 0.11 \% \cdot \mathrm{min}^{-1}\right)$ or before the control for mannitol $\left(0.82 \pm 0.10 \% \cdot \mathrm{min}^{-1}\right.$, $\left.0.76 \pm 0.10 \% \cdot \mathrm{min}^{-1}\right)$ in both groups, respectively.

The inhibitory effect of terbutaline on the mannitolinduced increase in clearance was transient, and within $10 \mathrm{~min}$ after intervention the clearance rate was increased $\left(1.58 \pm 0.39 \% \cdot \mathrm{min}^{-1}, 1.64 \pm 0.25 \% \cdot \mathrm{min}^{-1}\right)$ to a similar value observed with its placebo $(1.38 \pm$ $\left.0.37 \% \cdot \mathrm{min}^{-1}, 1.17 \pm 0.39 \% \cdot \mathrm{min}^{-1}\right)(\mathrm{p}>0.15)$ in the whole right lung in both groups, respectively (fig. 2). Differences in the clearance rate with the four interventions persisted for $40-50 \mathrm{~min}$ after the intervention interval. However, the total clearance achieved over 140 min from start of the intervention was similar with all interventions ( $p>0.05$ ) (fig. 1). The effects of interventions were similar in both groups $(\mathrm{p}>0.7)$.

The effects observed in the whole right lung, during the intervention and postintervention period, were also observed in the central and intermediate regions in both groups. In the peripheral region, the order of
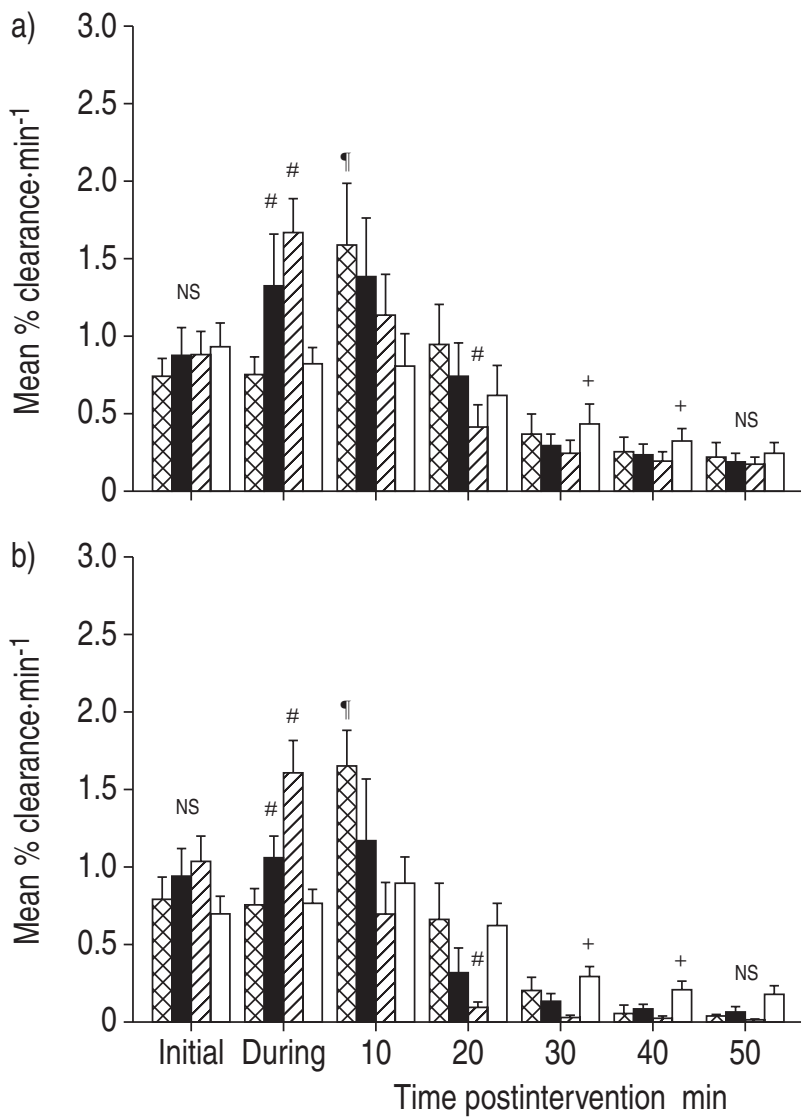

Fig. 2.-Mean per cent clearance per min of the four studies involving: 1) terbutaline before mannitol ( $)$; 2) placebo before

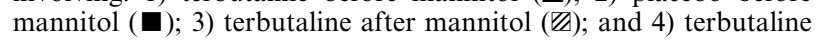
before mannitol control (cough control) ( $\square$ ) in the whole right lung, in the first $50 \mathrm{~min}$ in a) 11 asthmatic and b) nine healthy subjects. \#: significantly different from all other interventions; : significantly different from intervention 3 and 4 ; ${ }^{+}$: significantly different from intervention 3 only; NS: nonsignificant. 
administration of the two stimuli did not affect the clearance rate at any time throughout the whole time of measurement in both groups $(\mathrm{p}>0.1)$.

\section{Cough}

Inhalation of mannitol induced some coughing which was partly inhibited by terbutaline pretreatment in both groups (fig. 3). However, there was no correlation between the differences in the number of coughs and differences in clearance rate during intervention between terbutaline or its placebo inhaled before mannitol $\left(\mathrm{r}_{\mathrm{s}}=0.244\right.$ and $\left.0.176, \mathrm{p}>0.2\right)$ or between terbutaline inhaled before or after mannitol
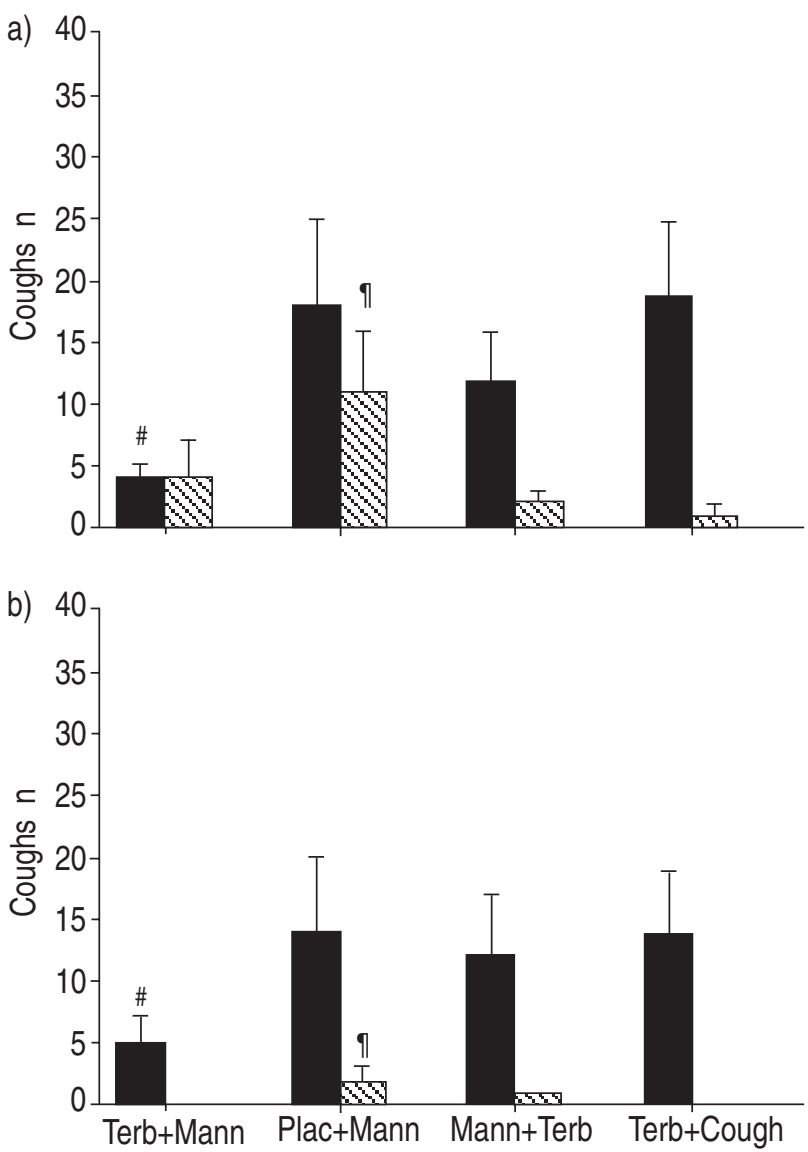

Fig. 3.-Mean number of coughs during intervention ( $\boldsymbol{\square})$ and postintervention $(\mathbb{\mathbb { N }})$ with the four studies involving: 1) terbutaline before mannitol (Terb+Mann); 2) placebo before mannitol (Plac+Mann); 3) terbutaline after mannitol (Mann+Terb); and 4) terbutaline before mannitol control (Terb+Cough), in a) 11 asthmatic and b) nine healthy subjects. The mannitol control involved voluntary cough matching the maximum number of coughs during mannitol inhalation. Coughing was significantly less during intervention only when terbutaline was inhaled before mannitol $(\mathrm{p}<0.001)$. After the intervention coughing was significantly more when placebo was inhaled before mannitol $(\mathrm{p}<0.01)$. The total number of coughs was the least with terbutaline inhaled before mannitol and the maximum with its placebo in both groups $(p<0.001)$. \#: significantly different during intervention from all other interventions; ": significantly different postintervention from all other interventions. $\left(r_{s}=0.206,0.479, p>0.2\right)$ in both asthmatic and healthy subjects, respectively.

\section{Penetration indices}

The intrapulmonary deposition of the radioaerosol was similar $(\mathrm{p}>0.5)$ in all study days in both groups (table 2).

\section{Discussion}

The key findings of this study were that the mannitol-induced increase in clearance was transiently inhibited by pretreatment with terbutaline and transiently enhanced when terbutaline was administered after mannitol in mild asthmatic and healthy subjects. There was no difference in the total clearance over 140 min from the start of the intervention with any order of administering mannitol and terbutaline.

It is unclear how the stimulatory pathways of terbutaline and mannitol would interact. An increase in MCC could result from increased CBF or improved properties of the mucus. Terbutaline can stimulate MCC via an increase in cAMP that regulates CBF. The mechanism whereby mannitol stimulates MCC is not clear but there are many potential factors that

Table 2. - Penetration indices (ratio of counts per pixel in the peripheral region to counts per pixel in the central region) for the 4 study days

\begin{tabular}{|c|c|c|c|c|}
\hline \multirow[t]{3}{*}{ Subjects } & \multicolumn{4}{|c|}{ Study days } \\
\hline & Terbutaline + & Placebo+ & Mannitol+ & Terbutaline \\
\hline & Mannitol & Mannitol & Terbutaline & $\begin{array}{c}+ \text { Mannitol } \\
\text { Control }\end{array}$ \\
\hline \multicolumn{5}{|c|}{ Asthmatic } \\
\hline 1 & 0.203 & 0.229 & 0.242 & 0.210 \\
\hline 2 & 0.320 & 0.291 & 0.288 & 0.293 \\
\hline 3 & 0.242 & 0.262 & 0.255 & 0.279 \\
\hline 4 & 0.367 & 0.317 & 0.369 & 0.373 \\
\hline 5 & 0.356 & 0.326 & 0.341 & 0.299 \\
\hline 6 & 0.218 & 0.249 & 0.241 & 0.246 \\
\hline 7 & 0.412 & 0.405 & 0.375 & 0.367 \\
\hline 8 & 0.402 & 0.419 & 0.435 & 0.436 \\
\hline 9 & 0.226 & 0.229 & 0.239 & 0.164 \\
\hline 10 & 0.204 & 0.167 & 0.208 & 0.245 \\
\hline 11 & 0.289 & 0.295 & 0.305 & 0.289 \\
\hline Mean & 0.294 & 0.290 & 0.300 & 0.291 \\
\hline SEM & 0.024 & 0.023 & 0.022 & 0.023 \\
\hline \multicolumn{5}{|l|}{ Healthy } \\
\hline 1 & 0.431 & 0.455 & 0.432 & 0.421 \\
\hline 2 & 0.200 & 0.165 & 0.207 & 0.235 \\
\hline 3 & 0.261 & 0.301 & 0.257 & 0.303 \\
\hline 4 & 0.346 & 0.323 & 0.360 & 0.367 \\
\hline 5 & 0.325 & 0.300 & 0.324 & 0.341 \\
\hline 6 & 0.314 & 0.294 & 0.310 & 0.298 \\
\hline 7 & 0.269 & 0.288 & 0.315 & 0.260 \\
\hline 8 & 0.413 & 0.442 & 0.394 & 0.391 \\
\hline 9 & 0.359 & 0.417 & 0.419 & 0.414 \\
\hline Mean & 0.330 & 0.340 & 0.340 & 0.340 \\
\hline SEM & 0.025 & 0.031 & 0.024 & 0.021 \\
\hline
\end{tabular}


can favourably influence ciliary activity and mucus properties [13-15].

As both mannitol [8] and terbutaline [3] stimulate MCC when administered separately, one might expect an augmented response when these agents are administered in combination, unless the system has reached its maximum response with only one stimulus. If there is no interaction the effect should be identical regardless of the order of administration of the two stimuli. However, when terbutaline was inhaled before mannitol ( $\beta_{2}$-receptor+osmotic stimulus) or before the control for mannitol ( $\beta_{2}$ receptor only) the immediate clearance rate was similar, implying that terbutaline inhibited the acute effect of mannitol. By contrast, the clearance rate was immediately increased when the terbutaline placebo was inhaled before mannitol (osmotic stimulus only) and it was further increased when terbutaline was administered after mannitol (osmotic $+\beta_{2}$-receptor stimulus).

In general, the effects of terbutaline in combination with mannitol on MCC in the present study are in agreement with those observed in in vitro studies of the effects of cAMP and terbutaline combined with a calcium agonist on the $\mathrm{CBF}$ in vitro $[26,27]$. In the present study, the only different finding was that the inhibition observed with terbutaline inhaled before mannitol was transient, lasting only for the duration of the intervention ( $20 \mathrm{~min})$. The clearance rate was increased within $10 \mathrm{~min}$ after the intervention. In contrast, the in vitro study [27] found that the inhibitory effect of terbutaline on the increase in CBF persisted even after the removal of terbutaline, suggesting that other factors play a role in vivo. However, the enhancement of the increase in MCC rate when terbutaline was inhaled after mannitol is in agreement with the in vitro findings showing the enhanced increase in $\mathrm{CBF}$ when terbutaline was introduced after the calcium agonist [27].

Intracellular calcium, like cAMP, regulates $\mathrm{CBF}$ and thus an increase in $\left[\mathrm{Ca}^{2+}\right]_{i}$ can contribute to an increase in clearance under normal conditions. Although an increase in $\left[\mathrm{Ca}^{2+}\right]_{\mathrm{i}}$ has not been confirmed in airway epithelial cells in response to mannitol, it has been confirmed in kidney cells [16]. It is reasonable to assume that a transient increase in $\left[\mathrm{Ca}^{2+}\right]_{\mathrm{i}}$ would simply occur as a result of water loss from the epithelial cells following the osmotic stimulus [17], even without an additional release from the intracellular stores or a calcium influx. However, additional increase in $\left[\mathrm{Ca}^{2+}\right]_{\mathrm{i}}$ is likely to occur as a result of the mediators $[22,23]$ released in response to mannitol, such as histamine and substance P [18]. Although terbutaline may inhibit the release of mediators from inflammatory cells [28], it is difficult to estimate the magnitude of the possible contribution of mediators in the asthmatics in this study, because there was no difference in the MCC responses between asthmatic and healthy subjects.

Both mannitol and terbutaline are expected to increase hydration in the airway lumen by different modes of action and also increase secretions [29, 30]. However, mannitol has the potential to decrease the density of the entanglements that mucin polymers form [13] and thus further facilitate clearance by ciliary action and cough. The transient effect of terbutaline could also be explained by its effect on cough but the findings do not support this.

The effects of terbutaline and mannitol administered in combination were manifest similarly in the central and intermediate regions but not in the peripheral region of the lung. Although the deposition pattern of terbutaline and mannitol in this study is unknown it is unlikely that it affected the results between studies. Significant differences of intrasubject deposition of mannitol between studies were not expected due to the normal baseline lung function and the small bronchodilating effect of terbutaline. It is not known how well airway narrowing was prevented in the asthmatic subjects when terbutaline was inhaled first, as lung function was not measured. The airway narrowing induced by mannitol may have affected the deposition of terbutaline inhaled afterwards, especially in the asthmatic subjects. However, there was no difference in the MCC responses between asthmatic and healthy subjects making it unlikely that differences in the intrasubject deposition of mannitol and terbutaline played a major role in this study, although it cannot be excluded.

As baseline MCC was not measured, there is no direct evidence that either mannitol or terbutaline stimulated MCC in these patients. However, it has been shown previously, using similar radioaerosol deposition patterns, that the mean baseline MCC at $60 \mathrm{~min}$ in healthy and asthmatic subjects is $\sim 30 \%$ [7, 31, 32]. Hence, the magnitude of the MCC in the present study $(>40 \%)$ suggests that the mucociliary system was stimulated by both mannitol and terbutaline. However, the aim of the study was not to compare the potency of terbutaline and mannitol on the stimulation of MCC but to investigate possible interactions when terbutaline and mannitol are administered in combination with doses likely to be used clinically. Although, the inhaled mannitol dose in asthmatic subjects differed from the dose in healthy subjects, changes in MCC were in the same direction in both groups with all combinations of terbutaline and mannitol. More importantly, the total clearance of radioactive mucus at $2 \mathrm{~h}$ after intervention was the same in both groups.

In conclusion, the pathways whereby the two stimuli increase mucociliary clearance may transiently interact, depending on the order of administration. However, the results of this study in subjects with normal lung function and normal mucociliary clearance do not suggest that the combination of the two agents will have adverse effects on the acute stimulation of the mucociliary system. These findings are relevant to patients with obstructive lung disease, who are the potential users of mannitol and are already prescribed $\beta_{2}$-agonists, as it may enhance clearance of mucus.

\footnotetext{
Acknowledgements. The authors would like to thank the technical staff of the Department of Positron Emission Tomography and Nuclear Medicine of Royal Prince Alfred Hospital for their help and the patients for taking part in the study.
} 


\section{References}

1. Sanderson MJ, Dirksen ER. Mechanosensitive and beta-adrenergic control of the ciliary beat frequency of mammalian respiratory tact cells in culture. Am Rev Respir Dis 1989; 139: 432-440.

2. Devalia JL, Sapsford RJ, Rusznak C, Toumbis MJ, Davies RJ. The effects of salmeterol and salbutamol on ciliary beat frequency of cultured human bronchial epithelial cells, in vitro. Pulm Pharmacol 1992; 5: 257-263.

3. Mortensen J, Groth S, Lange P, Hermansen F. Effect of terbutaline on mucociliary clearance in asthmatic and healthy subjects after inhalation from a pressurised inhaler and a dry powder inhaler. Thorax 1991; 46: 817-823.

4. Mortensen J, Lange $\mathrm{P}$, Nyboe J, Groth S. Lung mucociliary clearance. Eur J Nucl Med 1994; 21: 953-961.

5. Di Benedetto G, Manara-Shediac FS, Mehta A. Effect of cyclic AMP on ciliary activity of human respiratory epithelium. Eur Respir J 1991; 4: 789-795.

6. Lansley AB, Sanderson MJ, Dirksen ER. Control of the beat cycle of respiratory tract by $\mathrm{Ca}^{2+}$ and cAMP. Am J Physiol 1989; 263: L232-L242.

7. Daviskas E, Anderson SD, Gonda I, et al. Inhalation of hypertonic aerosol enhances mucociliary clearance in asthmatic and healthy subjects. Eur Respir J 1996; 9: 725-732.

8. Daviskas E, Anderson SD, Brannan JD, Chan H-K, Eberl S, Bautovich G. Inhalation of dry powder mannitol increases mucociliary clearance. Eur Respir $J$ 1997; 10: 2449-2454.

9. Robinson M, Regnis JA, Bailey DL, King M, Bautovich G, Bye PTP. Effect of hypertonic saline, amiloride \& cough on mucociliary clearance in patients with cystic fibrosis. Am J Respir Crit Care Med 1996; 153: 1503-1509.

10. Robinson M, Daviskas E, Eberl S, et al. The effect of inhaled mannitol on bronchial mucus clearance in cystic fibrosis patients: A pilot study. Eur Respir $J$ 1999; 14: 678-685.

11. Daviskas E, Anderson SD, Eberl S, Chan H-K, Bautovich G. Inhalation of dry powder mannitol improves clearance of mucus in patients with bronchiectasis. Am J Respir Crit Care Med 1999; 159: 1843 1848.

12. Daviskas E, Anderson SD, Eberl S, Chan H-K, Young IH. The $24 \mathrm{hr}$ effect of mannitol on the clearance of mucus in patients with bronchiectasis. Chest 2001; 119: 414-421.

13. King M, Rubin BK. Mucus controlling agents: Past and present. Resp Care Clin N Am 1999; 5: 574-594.

14. Winters SL, Yeates DB. Roles of hydration, sodium, and chloride in regulation of canine mucociliary transport system. J Appl Physiol 1997; 83: 1360-1369.

15. Wills P, Hall R, Chan W-M, Cole PJ. Sodium chloride increases the ciliary transportability of cystic fibrosis and bronchiectasis sputum on the mucus-depleted bovine trachea. J Clin Invest 1997; 99: 9-13.

16. Gillin AG, Star RA, Sands JM. Osmolarity-stimulated urea transport in rat terminal IMCD: role of intracellular calcium. Am J Physiol 1993; 265: F272-F277.

17. Morris MR, Doul IJM, Hallett MB. Osmotically induced cytosolic free $\mathrm{Ca}^{2+}$ changes in human neutrophils. Biochimica et Biophysica Acta 2001; 1538: 20-27.

18. Jongejan RC, de Jongste JC, Raatgee RC, Stijnen T, Bonta IL, Kerrebijn KF. Effect of hyperosmolarity on human isolated central airway. Br J Pharmacol 1991; 102: 931-937.

19. Wanner A, Maurer D, Abraham WM, Szepfalusi Z, Sielczak M. Effects of chemical mediators of anaphylaxis on ciliary function. J Allergy Clin Immunol 1983; 72: 663-667.

20. Wong LB, Miller IF, Yeates DB. Pathways of substance $\mathrm{P}$ stimulation of canine tracheal ciliary beat frequency. J Appl Physiol 1991; 70: 267-273.

21. Garrard CS, Mussatto DJ, Lourenco RV. Lung mucociliary transport in asymptomatic asthma: Effects of inhaled histamine. J Lab Clin Med 1989; 113: 190-195.

22. Rugolo M, Barzanti F, Gruenert DC, Hrelia S. Histamine activates phospholipase $\mathrm{C}$ in human airway epithelial cells via a phorbol ester-sensitive pathway. Am J Physiol 1996; 271: L665-L671.

23. Smith RP, Shellard R, Di Benedetto G, Magnus CJ, Mehta A. Interaction between calcium, neutral endopeptidase and the substance $\mathrm{P}$ mediated ciliary response in human respiratory epithelium. Eur Resp $J$ 1996; 9: 86-92.

24. Quanjer PH, Tammeling GJ, Cotes JE, Pederson OF, Peslin R, Yernault J-C. Lung volumes and forced ventilatory flows. Eur Respir J 1993; 6: Suppl. 16, 540.

25. Anderson SD, Brannan J, Spring J, et al. A new method for bronchial-provocation testing in asthmatic subjects using a dry powder of mannitol. Am J Respir Crit Care Med 1997; 156: 758-765.

26. Smith RP, Shellard R, Dhillon DP, Winter J, Mehta A. Asymmetric interactions between phosphorylation pathways regulating ciliary beat frequency in human nasal respiratory epithelium in vitro. J Physiol 1996; 496: 883-889.

27. Honeyman G, Kemp PJ, Dhilon DP, Winter JH, Mehta A. The $\beta_{2}$ agonist terbutaline makes the ciliary beat frequency of freshly isolated human airway cells refractory to calcium signaling. In: Baum GL, Priel Z, Roth Y, Liron N, Ostfeld E, eds. Cilia, mucus and mucociliary interactions. New York, Marcel Dekker, 1997; pp. 71-78.

28. O'Connor BJ, Fuller RW, Barnes PJ. Nonbronchodilator effects of inhaled $\beta_{2}$ agonists. Greater protection against adenosine monophosphate- than methacholineinduced bronchoconstriction in asthma. Am J Respir Crit Care Med 1994; 150: 381-387.

29. Dwyer TM, Farley JM. Mucus glycoconjugate secretion in cool and hypertonic solutions. Am J Physiol 1997; 272: L1121-L1125.

30. Leikauf GD, Ueki I, Nadel J. Autonomic regulation of viscoelasticity of cat tracheal gland secretions. J Appl Physiol 1984; 56: 426-430.

31. Daviskas E, Anderson SD, Gonda I, Chan HK, Cook $\mathrm{P}$, Fulton R. Changes in mucociliary clearance during and after isocapnic hypervetilation in asthmatic and healthy subjects. Eur Resp $J$ 1995; 8: 742-751.

32. Robinson M, Eberl S, Tomlinson C, et al. Regional mucociliary clearance in patients with cystic fibrosis. J Aerosol Med 2000; 13: 73-86. 